\title{
Gabriel Marcel se lewe en werk as agtergrond vir sy benadering tot God, Deel 1
}

\author{
Ernst Wolff \\ Tydelik-deeltydse dosent: Departement Godsdiens- en Sendingwetenskap \\ Universiteit van Pretoria
}

\begin{abstract}
Gabriel Marcel's life and work as background of his approach to God, Part 1

This essay gives an introduction to Gabriel Marcel that focuses on his approach to God. The biography of Marcel's life is sketched as the contingent origin and setting of his work. It is indicated where and how his life led him to practise philosophy the way he did. In the second half of the essay the unique nature of Marcel's philosophical style is sketched. Insight into Marcel's life and the nature of his work is inseparable from the continuous development of the contents of his thought.
\end{abstract}

\section{INLEIDING}

Ek bied hierdie artikel in twee dele oor die denke van Gabriel Marcel aan as 'n stimulering vir Hervormde teologiese selfbesinning, maar ook vir teologiese nadenke in die algemeen. Hervormde teologie word onder andere gekenmerk deur die feit dat dit oop is vir invloede vanuit die filosofie. Die debat oor die mate of wyse waarin Hervormde teologie 'n filosofiese teologie is (kyk Beukes 1994; Van Wyk 1994; Van Aarde 1995: 31) dui reeds daarop dat teologie (ook van ander kerke) van ontwikkelings in die filosofie kennis behoort te neem. Dit geld beslis ook vir die filosofie van Gabriel Marcel.

\footnotetext{
'Hierdie artikel is ' $n$ verwerking van die eerste deel van die BD-skripsie met dieselfde titel, wat gedurende September 1998 ingedien is en waarvoor prof dr L J S Steenkamp as studieleier opgetree het. Die skripsie is in groot dankbaarheid opgedra aan Izan Zybrands en Helena Dippenaar.
} 
Eksistensie-filosofie of filosofie wat daaraan verwant is, het op die Afrikaanse teologiese toneel verskyn onder andere deur die teologie van Barth, Bultmann, Brunner, maar ook deur direkte beïnvloeding van Kierkegaard, Heidegger, Jaspers en ander. Dit is ook belangrik om melding te maak van die invloed van Buber se personalisme, onder andere via Barth se konsepsie van die analogia relationis.

Een manier om die invloed van eksistensie-denke in Westerse teologie (waarvan Hervormde teologie tot op hede nog deel uitmaak) te verstaan, is om dit te sien teen die agtergrond van die reaksie op die krisis waarin die historiese kritiek die teologie gedompel het. Schleiermacher se teologie is in dié verband kenmerkend. Sy poging om op hierdie krisis te reageer behels 'n groter klem op die persoon van Jesus ten koste van die Christologiese dogma-tradisie. Jesus se innerlike sielelewe, sy onmiddellike bewussyn van God, word 'n produktiewe argetipe vir die verloste mens se verhouding met God. So tree ' $n$ antroposentriese wending in Protestantse teologiese denke in.

\begin{abstract}
Nicht in den objektiven geschichtlichen Fakten, sondern im subjektiven Bewußtsein des geschichtlichen Menschen ist Gott präsent. Auf der anderen Seite befreite er [Schleiermacher] den Glauben von dogmatischen Behauptungen und moralischen Postulaten und siedelte ihn im Herzen der menschlichen Person an als das inwendige "Gefühl der schlechthinnigen Abhängigkeit" von
\end{abstract} Gott.

(Moltmann 1988:65-6)

Met hierdie skuif verbind Schleiermacher die innerlike lewe van Jesus met dié van die gelowige en plaas die geloof só buite bereik van historiese of natuurwetenskaplike kritiek. Dit maak dit egter ook onmoontlik om kritiek vanuit die teologie teen die wetenskaplike en filosofiese rede te rig, omdat die diskoerse onversoenbaar is. So kom die vraag na die verhouding tussen geloof en rede weer sterk op die voorgrond.

Die teoloë in ons eeu, wat onder die invloed van die eksistensie-denke staan, is tot 'n groot mate kinders van Schleiermacher. Ons wat onder invloed van hierdie denkers staan, word steeds met dieselfde vrae gekonfronteer: Wat is die verhouding tussen geloof en rede? Kan gelowiges 'n verstaanbare gesprek oor hulle geloof in God met 'n nie- 
gelowige hê? Die huidige studie is 'n voorbereiding vir verdere studie oor die hulp wat Marcel se denke in hierdie verband kan wees.

Aangesien Marcel se denke nie los van sy lewe verstaan kan word nie, gaan ek in Deel 1 van hierdie artikel 'n lewenskets van hom aanbied. Ter voorbereiding van die uiteensetting van Marcel se denke (Deel 2) sal ek ook probeer om die aard van sy denke te skets.

\section{LEWENSKETS - BIOGRAFIESE PLASING AS OOR- SPRONG VAN DIE WERK VAN GABRIEL MARCEL}

Die lewensverhaal van Gabriel Marcel is meer as net 'n manier om met hom kennis te maak. Sy lewe en denke is onlosmaaklik verbind. Hy sê self oor die verhouding tussen sy lewe en werk:

Cela me donne à penser que le développement de ma réflexion a été dans une large mesure une explication [de ma vie - EW]. Tout me semble s'être passé comme si je n'avais réussi que progressivement à traiter comme matière à réflexion ce qui n'avait été d'abord pour moi qu'expérience vécue ... [Dit laat my dink dat die ontwikkeling van my denke tot 'n groot mate 'n verduideliking/uiteensetting van my lewe was. Dit lyk vir my of alles gebeur het so asof ek net geleidelik daarin geslaag het om dit wat in die eerste plek vir my deurleefde ervaring was, as onderwerp vir nadenke te hanteer ....]

(Marcel 1947:319)

Hy het self ook heelwat oor veral sy kinderjare opgeteken, soos byvoorbeeld die twee biografiese essays Regard en arrière (1947), An autobiographical essay ([1969] 1984) en tussen sy filosofiese werk deur, byvoorbeeld in die William James-lesings (Marcel 1969).

In hierdie skets van veral sy vroeë lewe wil ek probeer om aan te toon waar die wortels van Marcel se denke, en veral oor godsdiens en geloof, in sy lewe lê. 
Op 7 Desember 1889 is Gabriel Marcel as enigste kind in Monceau, Parys gebore. Sy pa, Henri Marcel, was 'n welgestelde, hooggeplaaste man. Hy was onder andere die Franse gesant na Swede, en direkteur van die Beaux-Arts en die nasionale museums. Aan hom het Marcel sy liefde vir musiek en teater te danke. Henri Marcel was oorspronklik Rooms-Katoliek, maar het hom heel vroeg daarvan losgemaak, onder andere onder invloed van sy vriend Ernest Renan. Uiteindelik is hy agnosties en beskou die Katolisisme as ongeldig en bygelowig. Wat lewenstyl betref, was hy pligsgetrou en gedissiplineerd.

Marcel se moeder is oorlede toe hy vier jaar oud was. Sy pa het toe met sy moeder se suster getrou. Dié was van oorsprong Joods, maar wend haar later tot 'n liberale Protestantisme. Sy was van mening dat haar rede haar nie toelaat om aan dogmas vas te klou nie en Marcel beskryf haar oriëntasie ook as religieuse agnostisisme.

Klein Gabriel was 'n "hyper-sensitive child, without question, but also turned in on himself, awkward, and no doubt, deeply anxious" (Marcel [1969] 1984:8) en hy skryf dit later daaraan toe dat sy lewe veral deur twee traumas oorheers is: die dood van sy moeder en swak gesondheid (Marcel [1969]1984:3). Hy is ook van mening dat sy gesondheid verswak is deur die geweldige druk wat sy skool en pa en stiefma op hom geplaas het om te presteer gedurende sy vyf jaar in die Lycée. Dit het vir hom gevoel of daar twyfel oor hom bestaan het en of daar nie tussen hom en sy werk onderskei is nie. Hy het onder die indruk gekom dat die huwelik van sy pa en tannie (wie se persoonlikhede gebots het) om sy ontwil aangegaan is en dat sy prestasie hierdie opoffering moes regverdig.

Dit was net met die grootste inspanning dat hy meestal eerste in die klas gestaan het. Sy kursus in filosofie was in hierdie tyd egter ' $n$ vorm van bevryding, omdat hy maklik hierin uitgeblink het. "Au plan des Idées, j’avais la possibilité de m’établir, de me créer un chez-moi, par delà tous les contacts meurtrissants que nous inflige la vie quotidienne. Philosopher, ce fut donc sans doute pour moi dès l'origine transcendre." [Op die vlak van Idees het ek die moontlikheid gehad om my te vestig, om vir my 'n tuiste te skep wat al die moordende kontakte/ervarings wat die daaglikse lewe my toedien, te bowe gaan. Om te filosofeer het dus vir my van die begin af beteken om te transendeer] (Marcel 1947:294). 
'n Ander kompensasie vir hierdie stres was musiek. Hy sou graag van die klavier sy loopbaan wou maak, maar ten spyte van 'n aansienlike begaafdheid, veral vir bladlees en improvisasie, was hy nie hiervoor goed genoeg nie. Veel later (1946-7) het hy kans gekry om van sy liedere en improvisasies te noteer. Die rol van musiek in Marcel se vorming kan nie oorskat word nie. Hy sê hiervan in sy William James-lesings: "I think I can say without hesitation that it is music, and music almost exclusively, which has been for me an unshakeable testimony af a deeper reality in which it seemed to me that everything fragmentary and unfulfilled on the sensory level would find fulfilment" (Marcel 1963:21). ${ }^{2}$

Hierdie suggestie van 'n "tweede werklikheid" het ook op 'n ander manier tot Marcel gekom. Soveel as wat sy stiefmoeder met haar positiewe en negatiewe dominering sy lewe as enkel kind gevul het, soveel het hy ook altyd bewus gebly van 'n misterieuse teenwoordigheid van sy oorlede moeder. Hierdie dualiteit in hom het 'n enorme invloed op hom uitgeoefen. Hy het vermoed dat “... cette polarité secrète de l'invisible et du visible a exercé sur ma pensée, et bien au delà de ma pensée exprimée, sur mon être mêrne, une influence occulte qui 'a dépassé infiniment toutes celles dont mes écrits présentent des traces discernables." [... hierdie geheime polariteit van die onsigbare en die sigbare 'n heimlike/bedekte invloed op my denke en veel verder as my uitgedrukte denke - op my wese self - uitgeoefen het, wat die naspeurbare spore daarvan, wat in my geskrifte teenwoordig is, oneindig oorskry] (Marcel 1947:303). Hierdie tema van die verhouding tussen die immanente - die waarneembare - en die transendente - die misterieuse - staan sentraal in Marcel se werk.

Die oorspronge van Marcel se aktiwiteit as dramaturg is veelvuldig. Eerstens tel die blootstelling aan sy pa, wat 'n literatuurkenner en uitstekende voorleser van toneelstukke was. Tweedens sien Marcel die oorsprong van die karakters wat hy in die lewe geroep het, in die ontbering om sonder broers of susters groot te word (sy eerste toneelstuk het hy reeds op die ouderdom van sewe jaar geskryf). Derdens het die intriges en

\footnotetext{
2 So byvoorbeeld die belangrike dagboekinskrywing waar die idee van die syn as oord van trou die eerste keer beslag gekry het: "De l'être comme lieu de la fídélité. D'où vient que cette formule qui a jailli en moi, à un instant donné du temps, présente pour moi la fécondité inépuisable de certaines idées musicales? Accès à l'ontologie" (Marcel 1935:55-56 my kursivering). Dit is veral die musiek van J S Bach wat vir Marcel geïnspireer het - iets wat ' $n$ mens behoort op te val, want Bach het onder vergelykbare omstandighede die nostalgie aan sy ouers wat hy vroeg verloor het, deur sy geloof en in sy werk probeer transendeer (sien L A Marcel 1976:17-18).
} 
botsings van mening en temperament in sy familie hom bewus gemaak van die onoplosbaarhede, wat selfs in oënskynlik eenvoudige menslike verhoudings voorkom (vgl Marcel 1947:296). Die relevansie van sy werk as dramaturg blyk uit die manier waarop sy drama en filosofie saam, uit dieselfde lewensituasie ontwikkel het. Dit neem al in sy vroeë filosofie vorm aan in sy bemoeienis met:

... die konkreten mitmenschlichen Beziehungen, die sich auf der rein intellektuellen Ebene nicht ordnen und ihre erstrebte Harmonie nur aus der Ahnung eines überrationalen Ursprunges erahnen lassen. Die dramatische Realisierung einer zwischenmenschlichen Szene geht der interpretierenden philosophischen Reflexion bei Marcel stehts voraus.

(Berning 1973:28)

Marcel waarsku dan ook daarteen om sy filosofie los van sy drama te probeer verstaan. Hy het egter nie pièces à thèse (toneelstukke waarin 'n filosofiese stelling gedemonstreer of gelegitimeer word) geskryf nie. Mens moet eerder sy drama verstaan as "szenische, dialogisierte Reflexion":

Diese möchte den Zuschauer zum aktiven Mitvollzug der Intersubjektivität einladen ohne jedes Mittel pathetischer Suggestion. Nur in diese Sinne dient ihm das Theater als Ausdruck der Resakralisation. Das Ziel ist eine Art spiritueller Konsonanz, in die hinein sich die Transzendenz als gegenwärtig offenbaren soll.

(Berning 1973:33)

Dat ek nie verder aan sy toneel aandag gee nie, is dus nie ' $n$ aanduiding dat dit onbelangrik is nie, maar moet toegeskryf word aan die perke van hierdie opstel en van my eie vermoëns. 


\title{
Gabriel Marcel se lewe en werk as agtergrond
}

Van kleins af en regdeur Marcel se lewe was hy gereeld op reise en vakansies. Van vroeg af is hy deur vreemde mense, plekke en name gefassineer. In hierdie drang om te ontdek, herken hy:

\begin{abstract}
... le souci métaphysique de découvrir l'intime au coeur du plus distant, c'està-dire au fond non point de triompher extérieurement de l'espace par la vitesse, mais de lui arracher un secret spirituel qui réduirait à néant sa puissance de ségrégation ... ce qui comptait pour moi, c'était de découvrir un ailleurs qui pût devenir essentiellement un ici. [...die metafisiese besorgdheid om die intieme in die hart van dit wat die verste is, te ontdek, dit wil sê, trouens, nie om uiterlik oor ruimte te seëvier deur spoed nie, maar om 'n geestelike geheim daaruit te haal, wat die mag tot skeiding tot niet maak ... dit wat vir my getel het was om 'n elders te ontdek, wat wesenlik 'n hier sou kon word.]
\end{abstract}

(Marcel 1947:305-6)

Hy ervaar sy vele staptogte as ontdekkingsreise, waarin hy die oorsprong van sy "honger na die konkrete" sien. Die prominensie wat die reise in Marcel se leefwêreld gehad het, word weerspieël in die titel van sy boek Homo Viator - die reisende mens.

Tussen 1906 en 1910 studeer Marcel aan die Sorbonne. Hier word hy gekonfronteer met die drie hoofstrome van die Franse filosofie van daardie tyd. Die dominante stroom was 'n wetenskaplike positivisme, tweedens 'n beweging van rasionalistiese Idealisme, wat by Kant aansluiting gevind het, derdens ' $n$ beweging in die tradisie van Franse spiritualiteit (kyk Berning 1973: 44-51).

Tydens die Eerste Wêreldoorlog was hy in diens van die Rooi Kruis, waar dit sy taak was om vir families inligting te gee oor soldate wat vermis geraak het op die slagveld. Die trauma waarmee hy hier gekonfronteer is, het 'n invloed uitgeoefen op sy persoonlike lewe, maar ook op sy filosofie (bv, sy personalisme en nadenke oor hoop). In hierdie tyd het hy para-/metapsigiese ervarings gehad, wat 'n verdere stukrag aan sy belangstelling in metafisika gegee het. Marcel verklaar ook dat hy oor "some mediumis- 
tic capacities" (Marcel [1969] 1984:21) beskik het. Sy nadenke hieroor het neerslag gevind onder andere in sy opstel De l'audace en Métaphysique (1947a).

As ons kyk na die ontwikkeling van Marcel se houding teenoor godsdiens dan blyk dit dat hy die agnostisisme van sy ouerhuis gedeel het. Op skool het die konfessionele onderrig, wat sommige vriende gekry het, vir hom geen aantrekking ingehou nie en het hy nie gevoel dat daar enige "geestelike voedsel" in godsdiens was nie. Hy was die mening toegedaan dat ' $n$ intelligente mens dalk tog nog Protestant sou kon wees, maar dat die Katolisisme te veel dwaashede en huigelary ingehou het.

Soos uit die lewenskets blyk, het sy belewenis van musiek, van die teater, van sy filosofiestudie, die ervaring van sy oorlede moeder se teenwoordigheid en later sy metapsigiese ervarings ' $n$ belangstelling of eerder ' $n$ behoefte aan transendensie by Marcel gewek. Hy werk in sy vroegste geskrifte met 'n totale sameloop in sy hantering van metafisika en godsdiens. Teen hierdie agtergrond kan die titel van sy beoogde doktorale proefskrif (wat hy egter nooit voltooi het nie), "Conditions of intelligibility of religious reality" (Marcel [1969]1984:18), verstaan word. Die gebruik van konsepsies wat eie is aan die Christelike denkwêreld soos geloof, God, hoop, liefde, gebed, trou, ensovoorts in die vroegste geskrifte val op.

Onder Marcel se universiteitsvriende tel 'n aantal Rooms-Katolieke, onder andere die groot neo-Thomis (vroeër Protestant) Jacques Maritain. Onder sy latere vriende tel bekendes soos Etienne Gilson (historikus van Middeleeuse filosofie) en François Mauriac (Nobel-prys wenner in letterkunde).

Met sy aanhang van Bergson vind hy op 'n manier reeds aansluiting by die Franse filosofiese tradisie van spiritualiteit. Maar selfs toe hy na die oorlog met Jacqueline Boegner trou (wat uit 'n Protestantse familie afkomstig was en eers veel later die Katolisisme aangeneem het), het hy nog nie aan bekering gedink nie. Sy skoonfamilie het wel by hom ' $n$ simpatie vir die Protestantisme gewek, maar dit is in die RoomsKatolieke Kerk wat hy uiteindelik in Maart 1929 gedoop is. Hy het teen die Protestantisme gekies omdat die keuse vir een van die verskillende denominasies (wat volgens hom sáám nie oor die essensiële punte enigheid het nie) te arbitrêr sou voorkom. Die globale visie van die Rooms-Katolieke Kerk het hom aangetrek. Hy het egter krities gebly teenoor bepaalde tendense in die Rooms-Katolieke Kerk (Marcel [1969] 1984:29) 
en het later ook met die pous gebots oor die manier waarop Marcel die vraagstuk van geboortebeperking hanteer het (vgl Marcel [1969] 1984:59-60).

Marcel sterf in Oktober 1973.

\section{TIPERING EN AARD VAN MARCEL SE DENKE}

Omdat die vorm en aard van Marcel se denke so nou verband hou met die inhoud daarvan, moet ek eers iets daaroor sê.

\subsection{Christelike eksistensialisme?}

Marcel se filosofie is die eerste keer as Christelike eksistensialisme getipeer in Sartre se L'Existentialisme est un Humanisme (1946). Hoewel huiwerig, het Marcel ook hierdie betiteling vir die band oor sy werk - Existentialisme chrétien: Gabriel Marcel (1947) aanvaar, waarin hy tewens ook ' $n$ bydrae gelewer het. Hierdie tipering van sy werk het Marcel in verband gebring met die eksistensialisme van Sartre en waarskynlik het Marcel by hierdie blootstelling gebaat. Tog het hy hom bewustelik van die betiteling as Christelike eksistensialis probeer losmaak, onder andere omdat dit die beeld geskep het dat hy maar net 'n Christelike weergawe van Sartre se filosofie aanbied. Alhoewel Marcel se denke die eksistensialisme voorafgaan en daar aansienlike verskille is in die aanslag van Sartre en Marcel, vertoon laasgenoemde se denke besliste eksistensialistiese trekke: hy stel die konsepsies "existensialisme" en "engagement" aan die Franse filosofie voor, hy begin die nadenke oor die lyflikheid van die mens, gebruik denkwyses wat ooreenkomste toon met die fenomenologie, ensovoorts (kyk Hocking 1954:442-444).

Die tipering "Christelik" moet ook met groot omsigtigheid gebruik word. Dit is opvallend dat konsepsies soos geloof, liefde, God, gebed, genade en ander alreeds in die Fragments Philosophiques (1909-1914) groot prominensie geniet het. Hy het hierdie terme dus begin gebruik 'n goeie twintig jaar voordat hy gedoop is. Hy gebruik die terme met ander woorde as filosoof, nie as teoloog nie, en die terme moet dus nie op die klank af aan ' $n$ Christelike verstaan daarvan gelykgestel word nie. Dieselfde geld vir die feit dat hy die benaming "Katoliek" laat in sy lewe afwys - hy wil hom nie aan spesifieke denominasionele inhoude verbind nie. 
Die Christelike geloofsinhoud vooronderstel nie sy denke nie, maar soos later sal blyk, kan filosowe hulle nie uit die konkrete leefwêreld abstraheer en hulle so van suiwer universele denke behelp nie. Deel van hierdie konkrete, historiese werklikheid is die gegewene van die Christendom en die geskiedenis daarvan. Die bestaan van Christelike denke, veral in ' $n$ westerse milieu, begunstig die ontwikkeling van idees, wat daarsonder dalk nie na vore sou kom nie - dit tree op as 'n bemesting in grond waaruit Christelike, sowel as nie-Christelike denke groei. Hierdie bodem noem Marcel para-Christelike sones en die werking hiervan het hy ondervind in sy twintig jaar se werk voor sy doop. Terwyl die Christelike geloof nie sy denke voorveronderstel nie, word sy denke wel daardeur beïnvloed (kyk Marcel [1933] 1949:88-91).

\subsection{Neo-Sokraties}

Die benaming "neo-Sokraties" is die uitvindsel van J Chenu, 'n Marokkaanse student van Marcel. Laasgenoemde het hierdie karakterisering vir homself toegeëien: “... wie einst Sokrates, so möchte er [Marcel] den Menschen unserer Zeit zu einer neuen Erfahrung der Tiefe seines eigenen Selbst und darin ursprünglicher Seins- und Werterfahrung verhelfen, in lebendig bewegt fragender, unaufhörlich aus- und zurückflutender, kreisender Denkform" (Ogiermann 1954:174).

Berning verduidelik die tipering as neo-Sokraties as volg:

Dabei denkt er [Marcel] weniger an eine Übereinstimmung mit allen Gehalten der platonischen Philosophie als an die sokratische Haltung der Wahrheitssuche, der Meditation und der Hoffnung auf die Unsterblichkeit. Sokrates, der unermüdlich das Gespräch mit der Jugend sucht und für den fragen auf dem Wege zur Unsterblichkeit kein Ende nimmt, ist ein Vorbild, mit dem sich Marcel am ehesten einverstanden weiß.

(Berning 1973:285) 


\subsection{Sisteem?}

Die poging om Marcel se denke te sistematiseer besorg aan die navorser besondere hoofbrekings. Marcel self het nooit 'n sisteem daargestel nie. Om die waarheid te sê, onder meer in die essay Ébauche d'une philosophie concrète [Skets vir 'n konkrete filosofie] (1940:92-126), het Marcel hom breedvoerig uitgespreek teen die wenslikheid daarvan om 'n sisteem daar te stel wat 'n eksklusiewe aanspraak is op 'n samehangende, geslote besit of houvas van die werklikheid. Sulke sisteme word as rigsnoere vir interpretasie van die werklikheid al te gou selfstandig en so neem dit later die plek van die werklikheid self in. Marcel wil eerder ' $n$ al hoe heftiger kritiek teen filosofiese sisteme beoefen - veral as dit gaan oor 'n filosofie as my sisteem. Hierteenoor probeer Marcel 'n filosofiese weg, dit is, 'n pad van voortdurende soeke (re-cherche) te volg. Dit moet, soos alle vorme van lewe, 'n proses wees van "dépenser, récupérer" - gebruik/verbruik en herwinning van denke (Marcel 1940:91). Solank as wat ' $n$ denker hiermee besig bly, kan hierdie denke sy of haar denke wees; sodra die proses stop, behoort die denke nie meer aan hom of haar nie. Vir Marcel is recherche altyd skeppend en dit hou nooit op om verbaas te raak nie. Voorbeelde van filosowe wat só gedink het, is volgens hom Kierkegaard, Schopenhauer en Nietzsche.

So 'n tipe filosofie toon die bytmerke van wat werklik is, soos Marcel sê. Dit is 'n konkrete filosofie wat nie kan bestaan "... sans une tension continuellement renouvelée et proprement créatrice entre le $J e$ et les profondeurs de l'ètre en quoi et par quoi nous sommes, ou encore sans une réflexion aussi stricte, aussi rigoureuse que possible, s'exerçant sur l'expérience la plus intensément vécue." [“... sonder 'n voortdurend hernuwende en werklik skeppende spanning tussen die $\mathrm{Ek}^{3}$ en die dieptes van die syn waarin en waardeur ons is, (en wat ook nie kan bestaan) sonder 'n ewe streng refleksie, wat so nougeset as moontlik moet wees, wat sigself voltrek op ervaring wat so intens moontlik deurleef is"] (Marcel 1940:98).

Hoe Marcel self aan hieraan probeer gehoor gee het, is die onderwerp van Deel 2 van my essay. Hy het die versoeking om sy eie gedagtes te sistematiseer, met opset gesystap. Die vorm waarin hy sy denke aanbied (essays, voordragte, dramas, outobiografieë en veral die dagboeke), is 'n geskikte manier om die noue verband tussen sy lewe,

\footnotetext{
${ }^{3}$ Die $E k$ is die geïnkarneerde mens - geen vorm van transendentale subjek nie.
} 
drama en filosofie, met inagneming van die inhoud van sy denke tot sy reg te laat kom. Dit wil egter nie sê dat hy bloot 'n paar losstaande idees op lukrake manier opdis nie. Dit word goed geillustreer in sy werke wat beskou word as die beste toegang tot die geheel Le mystère de l'être (twee volumes - 1951) en The existential background of human dignity $(1963)^{4}$ - waar die samehang en ontvouing van sy filosofiese en dramaturgiese werk, met verwysing na hulle samehang binne sy lewensverhaal, gekommentarieer word.

Die verhouding van filosofie tot die werklikheid in Marcel se denke moet dus nie gesien word as ' $n$ geslote vasstelling of presiese weergawe nie. Berning (1973:299) beskryf hierdie verhouding by Marcel as 'n "dialektische Annäherung":

Die Reflexion vermag diese Annäherung nur in eine sehr flexibilen Weise zu vollziehen. Jede begriffliche Aussage ist von Natur aus einseitig. Die Begriffsprache sagt das die Verhältnis dialektisch verbundener Gegensätze darum einseitig aus, weil sie nur entweder die These oder die Antithese zum ausdruck zu bringen vermag. Nur in einer beweglichen Reflexion, die sich von gegensätzlichen Ausgangspunkten der Einheit des Wirklichen nähert, ist eine auf das Ganze gerichtete Erfahrung möglich.

'n Voltooide geslote geheel kan nie reg laat geskied aan 'n geïnkarneerde homo viator se verhouding tot die werklikheid nie.

Wanneer ek in Deel 2 ' $n$ inleiding tot Marcel se filosofie gee, moet "filosofie" net gesien word as 'n samehang van sy denke (ek fokus op sy filosofiese denke) en dan bied ek dit ook net aan as 'n oorsig oor die belangrikste temas.

\section{Literatuurverwysings}

Berning, V 1973. Das Wagnis der Treue: Gabriel Marcels Weg zu einer konkreten Philosophie des Schöpferischen. München: Karl Alber.

Beukes, J 1994. Hervormde teologie is 'n filosofiese teologie. Die Hervormer 1 Maart $1994,6$.

4 Hierdie is die enigste boek van Marcel wat oorspronklik in Engels verskyn het. 
Gilson, E (éd) 1947. Existentialisme chrétien: Gabriel Marcel. Paris: Plon.

Hocking, W E 1954. Marcel and the ground issues of metaphysics. PPR 14/4, 439-469.

Marcel, G 1927. Journal Métaphysique. Paris: Gallimard.

- 1940. Essai de philosophie concrète. Paris: Gallimard.

- 1947. Regard en arrière, in Gilson 1947.

- 1947a. De l'audace en métaphysique. Revue de métaphysique et de morale 52, 233243.

- [1933]1949. Position et Approches concrètes du mystère ontologique. Paris: Vrin.

- 1963. The existential background of human dignity. Harvard, MS: Harvard University Press.

— [1969] 1984. An autobiographical essay, in Schilpp \& Hahn 1984.

Marcel, L-A 1976. Bach. Paris: Seuil.

Moltmann, J 1988. Was ist Theologie heute? Twei Beiträge zu ihrer Vergegenwärtgung. Basel: Herder.

Ogiermann, H 1954. Gottes Existenz im Denken Gabriel Marcels. Scholastik 29, 174209.

Schilpp, P A \& Hahn, L E (eds.) 1984. The philosophy of Gabriel Marcel. La Salle: Open Court.

Van Aarde, A G 1995. Kerk en teologie op pad na die derde millennium: 'n Paradigmatiese verskuiwing van middelmatige aard. HTS 51(1), 13-38.

Van Wyk, G M J 1994. Oor die grens(e) tussen teologie en filosofie. Die Hervormer 1 April 1994, 5. 